\title{
STUDI KADAR Pb PADA MAKANAN JAJANAN DODOL CIKAL, ONDE-ONDE, KUE APEM DAN GORENGAN TAHU ACI DI PASAR BANJARAN-ADIWERNA, KABUPATEN TEGAL TAHUN 2016
}

\author{
Nurul Itsnaeni' ${ }^{1)}$, Susiyanti ${ }^{2)}$ \\ Jurusan Kesehatan Lingkungan, Politeknik Kesehatan Kemenkes Semarang, \\ Jl.Raya Baturaden KM 12 Purwokerto, Indonesia
}

\begin{abstract}
Abstrak
Pb merupakan salah satu zat pencemaran udara yang berasal dari sisa pembakaran kendaraan bermotor. Udara yang tercemar oleh partikel dan gas ini dapat menyebabkan gangguan kesehatan yang berbeda tingkatan dan sejenisnya, gangguan tersebut terutama terjadi pada fungsi fatal dari organ tubuh seperti paru-paru dan pembuluh darah atau menyebabkan iritasi pada mata dan kulit. Jumlah kadar Pb yang ada di udara dapat mempengaruhi lingkungan disekitarnya antara lain makanan yang di jual pinggir jalan khususnya makanan jajanan. Tujuan penelitian ini adalah untuk mengetahui ada dan tidaknya kadar Pb pada makanan jajanan, prilaku penjamah serta kepadatan kendaraan di Pasar Banjaran-adiwerna, Kabupaten Tegal tahun 2016. Metode penelitian yang digunakan adalah deskriptif, yaitu untuk mengetahui kadar Pb pada makanan jajanan di Pasar Banjaran-Adiwerna, Kabupaten Tegal tahun 2016. Pengumpulan data dilakukan dengan pemeriksaan kadar Pb di Laboratorium Kesehatan Lingkungan Kota Tegal. Penyajian dilakukan dengan cara mendeskripsikan data dalam bentuk narasi. Hasil yang diperoleh dari penelitian menunjukan tidak adanya kadar Pb pada makanan jajanan dodol cikal, onde-onde, kue apem dan gorengan tahu aci. Perilaku penjamah makanan jajanan tiga pedagang, dua pedagang dikategorikan cukup dengan skor $75 \%$ dan satu pedagang dikategorikan kurang dengan skor $50 \%$. Kepadatan kendaraan di sekitar lokasi rata-rata 0,102 smp/jam. Makanan jajanan yang diperjual belikan di Pasar Banjaran-Adiwerna, Kabupaten Tegal tidak mengandung timbal Pb. Bagi penjamah makanan sebaiknya menggunakan celemek, tutup kepala dan menyediakan alat penjepit makanan.
\end{abstract}

Kata kunci $\quad$ : Timbal, makanan jajanan, perilaku penjamah

\begin{abstract}
$\mathrm{Pb}$ is one of the substances of air pollution that comes from combustion vehicles. The air contaminated by particles and gases can cause health problems of different levels and the like, the disorder mainly occurs in fatal function of organs such as the lungs and the blood vessels or cause irritation to the eyes and skin. The amount of Pb in the air can affect the surrounding environment include food sold roadside snack foods in particular. The purpose of this study was to determine the presence and absence $\mathrm{Pb}$ on street food, behavior handlers as well as the density of vehicles in Banjaran Market-Adiwerna, Tegal 2016. The research method is descriptive, ie to determine levels of $\mathrm{Pb}$ in food hawker-Adiwerna Banjaran Market, Tegal 2016. Data collection was performed by examination of $\mathrm{Pb}$ in Environmental Health Laboratory Tegal. Presentation made by describing the data in narrative form. The results of the study showed no Pb on street food dodol origin, dumplings, cakes and fried apem know aci. Behavior hawker food handlers are three traders, two merchants categorized enough with a score of $75 \%$ and the merchants categorized less with a score of 50\%. The density of vehicles in the vicinity of the average $0.102 \mathrm{smp} /$ hour. Snack food is traded on the Market-Adiwerna Banjaran, Tegal regency does not contain lead Pb. Food handlers should use aprons, headgear and providing food tongs.
\end{abstract}

Keywords : Lead, snack foods, behaviors handlers

\section{PENDAHULUAN}

Pembangunan kesehatan bertujuan untuk meningkatkan kesadaran, kemauan, dan kemampuan hidup sehat bagi setiap orang agar terwujud derajat kesehatan masyarakat yang setinggi-tingginya, sebagai investasi bagi pembangunan sumber daya manusia yang produktif secara sosial dan ekonomis (Undang-undang No.36, 2009). Kondisi lingkungan yang diharapkan dalam pembangunan kesehatan

1) Email : itsnaeni95@gmail.com

2) Email : fatihanam@gmail.com adalah lingkungan yang kondusif bagi terwujudnya keadaan sehat, yaitu lingkungan yang bebas dari polusi, terjadinya air bersih, sanitasi lingkungan yang baik, perumahan, pemukiman yang sehat, perencanaan kawasan kesehatan, serta terwujudnya masyarakat yang saling tolong menolong dalam memelihara nilai-nilai budaya bangsa.

Pencemaran atau polusi adalah suatu kondisi yang telah berubah dari bentuk asal pada keadaan 
yang lebih buruk. Pergeseran bentuk tatanan dari kondisi asal pada kondisi yang buruk ini dapat terjadi sebagai terjadi sebagai akibat masukan dari bahan-bahan pencemar atau polutan. (Heryando Palar, 1994, hal 10).

Menurut Undang-undang RI No.23,1997, pencemaran udara adalah masuk atau dimasuknya makhluk hidup, zat, energi dan atau komponen lain ke dalam udara dan atau berubahnya tatanan (komposisi) udara oleh kegiatan manusia atau proses alam, sehingga kualitas udara turun sampai ketingkat tertentu yang menyebabkan udara kurang atau tidak dapat berfungsi lagi sesuai dengan peruntukannya. Salah satu pencemaran udara ditimbulkan dari sisa pembakaran kendaraan bermotor.

Pengendalian pencemaran udara akibat kendaraan bermotor, pada dasarnya merupakan salah satu bagian dalam pengendalian pencemaran udara akibat system dan sarana transportasi. Kendaraan bermotor dalam hal ini merupakan salah satu sumber pencemaran yang terkait dengan sistem dan sarana transportasi. Kendaraan bermotor adalah sumber langsung yang mengemisikan pencemar ke atmosfer, sedangkan jumlah trip dan kendaraan perkilometer yang menentukan besaran emisi, lebih banyak ditentukan oleh faktor perkotaan dalam sistem transportasi yang ada. (Moestikahadi Soedomo, 2001, hal 231-232).

Sumber pencemaran udara kegiatan kendaraan bermotor di darat. Kendaraan bermotor merupakan sumber pencemaran udara yaitu dengan dihasilkan salah satunya merupakan bahan logam Pb. Dampak pencemaran udara pada dasarnya berbentuk partikel (debu, aerosol, dan $\mathrm{Pb}$ ). Udara yang tercemar oleh partikel dan gas ini dapat menyebabkan gangguan kesehatan yang berbeda tingkatan dan sejenisnya, gangguan tersebut terutama terjadi pada fungsi fatal dari organ tubuh seperti paru-paru dan pembuluh darah, atau menyebabkan iritasi pada mata dan kulit.

Berdasarkan survei Pasar Banjaran-Adiwerna Kabupaten Tegal, penjual makanan jajanan terletak di lokasi parkir, sehingga kendaraan banyak yang berhenti dan berlalu lalang yang memungkinkan makanan jajanan terpapar kadar $\mathrm{Pb}$ maka peneliti ingin melakukan penelitian Karya Tulis Ilmiah yang berjudul "Studi Kadar Pb Pada Makanan Jajanan Dodol, Onde-Onde, Kue Apem dan Gorengan Tahu Aci di Pasar Banjaran-Adiwerna, Kabupaten Tegal Tahun 2016”.

Pencemaran udara karena partikel debu biasanya menyebabkan penyakit pernapasan kronis seperti bronchitis khronis, emfiesma paru, asma bronchial dan bahkan kanker paru. $\mathrm{Pb}$ yang tinggi di udara dapat mengganggu pembentukan sel darah merah. Gejala keracunan dini mulai ditunjukan dengan terganggunya fungsi enzim untuk pembentukan sel darah merah, yang pada akhirnya dapat menyebabkan gangguan kesehatan lainnya seperti anemia, kerusakan ginjal dan lain-lain. Sedangkan keracunan $\mathrm{Pb}$ bersifat akumulatif.
(Moestikahadi Soedomo, 2001, hal 4-8). Jumlah Pb yang ada di udara dapat mempengaruhi lingkungan disekitarnya antara lain makanan yang di jual di pinggir jalan khususnya makanan jajanan.

Tujuan penelitian ini yaitu sebagai berikut : mengetahui jumlah kadar $\mathrm{Pb}$ pada jajanan dodol cikal, onde-onde, kue apem dan gorengan tahu aci di Pasar Banjaran-Adiwerna, Kabupaten Tegal.

\section{METODE PENELITIAN}

Jenis penelitian ini yang digunakan pada penelitian adalah penelitian deskripsi, yaitu mengetahui ada tidaknya kadar $\mathrm{Pb}$ pada makanan jajanan yang di perjualbelikan di Pasar BanjaranAdiwerna, Kabupaten Tegal.

Analisis data yang digunakan pada penelitian secara deskriptif. Penyajian dilakukan dengan cara mendeskripsikan data dalam bentuk tabel dan narasi. Dari hasil pemeriksaan Laboratorium dibandingkan dengan peraturan perundang-undangan yang berlaku, yaitu BPOM RI No. HK.00.06.1.52.4011 tahun 2009 tentang Penetapan Batas Maksimal Cemaran Mikroba dan Kimia dalam Makanan.

Penelitian dilakukan di lokasi penjualan makanan jajanan di Pasar Banjaran-Adiwerna, Kabupaten Tegal.

Materi penelitian berkaitan dengan penyehatan makanan dan minuman, jumlah kadar $\mathrm{Pb}$ yang terdapat pada makanan jajanan dodol cikal, ondeonde, kue apem dan gorengan tahu aci di Pasar Banjaran-Adiwerna, Kabupaten Tegal.

Subjek penelitian ini adalah makanan jajanan di Pasar Banjaran-Adiwerna, Kabupaten Tegal. Sampel yang akan diambil terdiri dari 4 jenis jajanan makanan basah tanpa kemasan yaitu dodol cikal, onde-onde, kue apem dan gorengan tahu aci. Pengambilan sampel dilakukan pada pagi pada pukul 08.00-09.00 dan siang pada pukul 13.00-14.00 WIB, karena pada jam tersebut padatnya kendaraan yang melintas.

Pasar Banjaran terletak di daerah Adiwerna Kabupaten Tegal. Pasar Banjaran menyediakan berbagai macam barang mulai dari buah-buahan, sayur-sayuran, aneka jajanan pasar sampai peralatan sekolah. Tempat parkir Pasar Banjaran cukup memadai. Pasar Banjaran juga terdapat Swalayan Banjaran Permai yang menyediakan berbagai macam kebutuhan pokok manusia. Pasar Banjaran biasanya dikunjungi pembeli dari berbagai macam penjuru desa yang berada di Kabupaten Tegal oleh karena itu pasar Banjaran menjadi Pusat perbelanjaan yang terjangkau bagi masyarakat daerah Tegal khususnya daerah Adiwerna.

Data khusus yang diambil meliputi kadar $\mathrm{Pb}$ pada makanan jajanan di Pasar Banjaran-Adiwerna, Kabupaten Tegal. Waktu, kepadatan, perilaku. Data ini diperoleh dari hasil pemeriksaan kadar $\mathrm{Pb}$ pada makanan jajanan di Laboratorium Kesehatan Lingkungan Kota Tegal serta observasi tempat penelitian. Dalam penelitian ini berupa dokumen 
yang diperoleh dari pihak pengelola Pasar BanjaranAdiwerna, Kabupaten Tegal.

Observasi ini merupakan pengumpulan data dengan cara pengamatan di lokasi tersebut, meliputi kepadatan kendaraan, perilaku penjamah makanan jajanan di Pasar Banjaran-Adiwerna, Kabupaten Tegal. Pemeriksaan Laboratorium Merupakan pengumpulan data dengan cara pemeriksaan kadar $\mathrm{Pb}$ di Laboratorium Kesehatan Lingkungan Kota Tegal.

\section{HASIL DAN PEMBAHASAN}

\section{Gambaran Umum}

a. Gambaran Umum Pasar BanjaranAdiwerna, Kabupaten Tegal.

Pasar Banjaran berdiri pada tahun 1994, lokasi penelitian adalah di Pasar BanjaranAdiwerna, Kabupaten Tegal dengan luas $17.380 \mathrm{~m}^{2}$. Bagian-bagian jenis prasarana yang terdapat di Pasar Banjaran-Adiwerna, Kabupaten Tegal antara lain:
1) Kios
: 246
2) Loos
: 36
3) Pedagang : 553
4) Jumlah Kios : 140
5) Jumlah Loos : 233
6) Lemprakan : 35
7) PKL : 87

Pasar Banjaran-Adiwerna, Kabupaten Tegal mempunyai struktur kepengurusan yang terdiri dari Kepala Pengelola Pasar, Ka.Subag TU dimana Ka.Subag TU memiliki Staf 1 bagian Retribusi terdiri dari 6 orang, Staf 2 bagian Administrasi terdiri dari 3 orang dan Staf 3 bagian Kebersihan terdiri dari 2 orang.

b. Gambaran Umum Pedagang

Makanan Jajanan Pasar BanjaranAdiwerna, Kabupaten Tegal. Penelitian kadar Pb pada makanan jajanan dilakukan dengan cara pembelian sampel pada pedagang makanan jajanan di Pasar Banjaran-Adiwerna, Kabupaten Tegal. Jumlah pedagang makanan jajanan di Pasar Banjaran ada 3 pedagang, peneliti mengambil sampel pada makanan jajanan yang tidak terbungkus dengan plastik atau kemasan yang memungkinkan tercemar oleh kadar $\mathrm{Pb}$ di udara, maka peneliti melakukan pengambilan sampel pada 3 pedagang makanan jajanan diantaranya Dodol Cikal, Onde-onde, Kue Apem dan Gorengan Tahu Aci. Adapun data yang telah diperoleh antara lain :

Daftar Nama Penjual Makanan Jajanan Dodol Cikal, Onde-onde, Kue Apem dan Gorengan Tahu Aci di Pasar BanjaranAdiwerna, Kabupaten Tegal

\begin{tabular}{ccccc}
\hline $\begin{array}{c}\mathrm{N} \\
0\end{array}$ & Nama & $\begin{array}{c}\text { Jenis } \\
\text { Kelamin }\end{array}$ & Umur & $\begin{array}{c}\text { Pend } \\
\text { idika } \\
\mathrm{n}\end{array}$ \\
\hline 1 & EK & Laki-laki & $\begin{array}{c}45 \\
\text { tahun }\end{array}$ & SMP \\
2 & RS & Perempuan & $\begin{array}{c}62 \\
\text { tahun } \\
47\end{array}$ & SD \\
3 & LS & Perempuan & $\begin{array}{c}47 \\
\text { tahun }\end{array}$ & SD \\
\hline
\end{tabular}

2. Gambaran Khusus

a. Kadar $\mathrm{Pb}$ pada Makanan Jajanan dan Waktu Pemaparan.

Setelah dilakukan pemeriksaan terhadap makanan jajanan di Laboratorium Kesehatan Lingkungan di Kota Tegal, yaitu terdiri dari 4 sempel makanan jajanan diantaranya : dodol cikal, onde-onde, kue apem dan gorengan tahu aci. Pengambilan sampel pada pukul 08.25 dan 13.35 WIB (pemaparan selama 6 jam) di dapatkan hasil bahwa sampel tidak melebihi nilai ambang batas $\leq 0,25$ ppm dengan hasil negative.

Hasil telah dijelaskan bahwa 24 sampel makanan jajanan dengan jenis dodol cikal, onde-onde, kue apem dan gorengan tahu aci, yang telah diperiksa di Laboratorium Kesehatan Lingkungan Kota Tegal dikatakan semuanya negatif tidak mengandung kadar $\mathrm{Pb}$ walaupun sudah mengalami waktu pemaparan selama 6 jam, pengambilan sampel pada 3 pedagang pada pukul 08.25-09.00 pagi waktu pemaparan 25 menit dan pengambilan sampel pada 3 pedagang pukul 13.35-14.00 siang waktu pemaparan 35 menit, menurut peraturan perundang-undangan yang berlaku, yaitu BPOM RI No. HK.00.06.1.52.4011 tahun 2009 tentang batas maksimal cemaran mikroba dan kimia dalam makanan sampel yang didapatkan memenuhi syarat yang memiliki nilai ambang batas $\leq 0,25 \mathrm{ppm}$, berdasarkan hasil penelitian sampel tidak terdapat kadar $\mathrm{Pb}$ pada makanan tetapi jika makanan dikonsumsi secara terus menerus dalam jumlah yang banyak kadar $\mathrm{Pb}$ akan terakumulasi pada tubuh yang mengakibatkan berbagai macam penyakit akut maupun kronis pada tubuh manusia.

Pengambilan sampel dalam satu hari yaitu dua kali pada pukul 08.25 WIB dan pukul 13.35 WIB, pemeriksaan sampel di Laboratorium Kesehatan Lingkungan Kota Tegal menggunakan alat test kit, dimana tes kit tersebut akan menunjukkan kadar $\mathrm{Pb}$ positif apabila dalam makanan terdapat kadar $\mathrm{Pb}$ maksimum 20 mg/l Pb, apabila 
kadar $\mathrm{Pb}$ dalam makanan kurang dari 20 $\mathrm{mg} / \mathrm{l} \mathrm{Pb}$, maka sampel tersebut negative.

Berdasarkan Peraturan Kepala Badan Pengawas Obat dan Makanan RI Nomor HK.00.06.1.52.4011 tentang penetapan batas maksimum cemaran mikroba dan kimia dalam makanan disebutkan bahwa cemaran kimia adalah cemaran dalam makanan yang berasal dari unsur atau senyawa kimia yang dapat merugikan dan membahayakan kesehatan manusia, dapat berupa cemaran logam berat, cemaran mikotoksin, cemaran antibiotik, cemaran sulfonamida atau cemaran kimia lainnya. Dalam peraturan ini disebutkan bahwa untuk batas maksimum cemaran kadar $\mathrm{Pb}$ untuk pangan olahan adalah $\leq 0,25 \mathrm{ppm}$. Jika dibandingkan dengan hasil peneliti sampel jajanan tidak satupun yang mengandung kadar $\mathrm{Pb}$.

Akan tetapi jika tidak memperhatikan aspek cemaran kadar $\mathrm{Pb}$ terutama dari udara yang tercemar dan mengkomsumsi jajanan dalam jumlah yang banyak, maka kadar $\mathrm{Pb}$ yang masuk melalui makanan atau minuman tersebut akan menuju faring kemudian dibawa ke saluran cerna. Selanjutnya kadar $\mathrm{Pb}$ akan tersimpan dalam darah yang lama kelamaan akan terakumulasi. Menurut Habrianti, apabila konsentrasi timbal terakumulasi hingga $10 \mu \mathrm{g} / \mathrm{dl}$ pada seorang anak, maka poin IQ -nya cenderung menurun 2,5 poin, bahkan bisa kehilangansampai 4 poin IQ pada usia tujuh tahun.dampak lain anak mengalami gejala anemia, hambatan dalam pertumbuhan, perkembangan kognitif buruk, system kekebalan tubuh melemah disertai gejala autis, bahkan dapat terjadi kematian dini.

Pengaruh yang ditimbulkan dari peningkatan kadar $\mathrm{Pb}$ pada makanan jajanan antara lain lamanya pemaparan dan cara penyajian makanan. Lamanya pemaparan selama 6 jam dari pukul 08.0014.00 WIB juga dapat mempengaruhi adanya kadar $\mathrm{Pb}$ pada makanan jajanan, semakin banyak mengkonsumsi makanan jajanan yang terpapar oleh gas buang, maka makanan tersebut dapat menjadikan penumpukan kadar pb pada tubuh yang dapat mempengaruhi kesehatan pada masyarakat mulai dari dampak kronis sampai akut. Makanan jajanan yang berminyak lebih banyak kadar $\mathrm{Pb}$ dalam pemaparan jangkauan panjang, karena partikel pada kadar $\mathrm{Pb}$ mudah menempel pada minyak, selain itu minyak yang digunakan berkali-kali dan tidak tertutup akan mudah terkontaminasi oleh gas buang. Pencegahan terjadinya peningkatan kadar
$\mathrm{Pb}$ pada makanan jajanan, lebih baik menggunakan pembungkus atau kemasan agar makanan jajanan tersebut lebih aman, sehingga meminimalisir kadar $\mathrm{Pb}$ pada makanan serta memperhatikan makanan jajanan yang tersaji ketika dalam keadaan terbuka segeralah menutup kembali pada saat pembeli sudah tidak memilih makanan jajanan. Pembuatan etalase pada tempat penyajian makanan juga berperan penting dalam pencegahan masuknya kadar $\mathrm{Pb}$ pada makanan.

b. Kepadatan Kendaraan

bahwa kedua titik diperoleh hasil kriteria arus stabil pada titik 1 dan 2 yaitu sepeda motor dan mobil, kriteria arus stabil dan bebas pada titik 3 dan 4 yaitu sepeda motor dan mobil, kapasitas kepadatan kendaraan yaitu nol. Pada titik 1 sebelah utara dari pedagang terdiri sepeda motor 0,00 smp/jam dan mobil 0,00 smp/jam, gas buang yang diperoleh kendaraan yang melintas dari arah utara ke selatan tidak mengkontaminasi makanan jajanan karena arah angin berlawanan dari gas buang kendaraan dan kemungkinan kecil tidak kontaminasi timbal oleh udara luar karena kepadatan kendaraan yang kurang juga mempengaruhi kontaminasi timbal. Pada titik 2 sebelah selatan dari pedagang terdiri sepeda motor $0,00 \mathrm{smp} / \mathrm{jam}$ dan mobil 0,00 smp/jam, sedangkan gas buang kendaraan yang melintas dari arah selatan ke utara karena arah angin berlawanan dari pedagang ke gas buang kendaraan selain itu juga kepadatan kenadraan yang melintas yang kurang juga mempengaruhi kontaminasi timbal, sementara titik ke 3 di jalan raya sebelah utara pasar terdiri dari sepeda motor $0,76 \mathrm{smp} / \mathrm{jam}$ dan mobil 0,24 smp/jam kontaminasi timbal dan kepadatan kendaraan lebih kecil karena dipinggir jalan terdapat pedagang yang memakai tenda, selain itu pada titik ke 4 di jalan raya sebelah selatan pasar terdiri sepeda motor 0,71 smp/jam dan mobil 0,17 smp/jam, kemungkinan terkontaminasi timbal dan kepadatan kendaraan lebih kecil, karena disepanjang jalan pasar Banjaran terdapat pedagang bertenda.

Cara yang dilakukan agar tidak makanan jajanan yaitu tidak berjualan di lokasi yang berdekatan dengan kendaraan yang berlalu lalang. Jika tidak makanan yang disajikan tertutup rapat sehingga makanan tersebut tidak mudah terkontaminasi cemaran logam berat, cemaran mikotoksin, cemaran antibiotik, cemaran sulfonamida atau cemaran kimia lainnya.

c. Perilaku Penjamah 
Berdasarkan hasil observasi selama 6 jam ke 3 pedagang melakukan aktivitas seperti mainan gaget, menguap, menggaruk kepala, berbincang, batuk, selain itu terdapat konsumen atau orang lewat yang merokok, penjajah jajanan menyajikan makanannya di pinggir jalan ada yang tertutup dan tanpa penutup, dari 3 pedagang selama menyajikan makanan jajanan tidak menutup makanan yang terbuka meskipun pedagang berjualan di lokasi kendaraan yang berlalu lalang. Sebagaimana yang telah kita ketahui bahwa sumber-sumber pencemar kadar $\mathrm{Pb}$ diantaranya berasal dari gas buang kendaraan bermotor yang mencemari jajanan yang dipajangkan tanpa wadah penutup serta alat-alat berbahan logam maupun kertas bekas atau kertas yang bertulis tinta juga menjadi salah satu sumber kontaminasi kadar $\mathrm{Pb}$ pada pangan. terutama jika digunakan saat pangan dalam keadaan panas.

Kondisi jalanan yang dipenuhi polusi udara dapat mempengaruhi kehygenesan kondisi makanan. Makanan disajikan dan dikonsumsi dalam kondisi suhu yang tidak lagi layak, kondisi makanan ini dapat menarik lalat dan serangga lainnya. Resiko makanan yang terbuka diantaranya terinfeksi gastrointestinal adalah kuman penyebab infeksi pencernaan dapat tanpa sengaja tercampur di dalam makanan jajanan pinggir jalan. Jenis infeksi inilah yang akan menyebabkan diare atau muntah, orang dewasa cenderung memiliki system imun yang lebih kuat jika dibandingkan dengan anak-anak dan orang berusia lanjut.

Dari ketiga perilaku penjamah makanan jajanan tersebut antara lain :

1) Penjual tidak merokok pada saat berjualan

Penjual tidak merokok pada saat berjualan, akan tetapi terdapat konsumen yang merokok, jika terdapat asap rokok dihadapan makanan, maka zat aditif yang ada di dalam rokok masuk ke dalam makanan melalui asap rokok dan tidak baik untuk kesehatan manusia jika mengkonsumsi jumlah terlalu banyak.

2) Makanan terhindar dari asap kendaraan bermotor

Jumlah pedagang di pasar ada 3 pedagang makanan jajanan, di pasar Banjaran berjualan di luar pasar yang berdekatan dengan kendraaan yang berlalu lalang, makanan yang baik dan hygene yang terhindar dari bahanbahan kimia yang berbahaya, dan tidak boleh terpapar sinar matahari secara langsung. Jika makanan terpapar asap kendaraan, maka makanan tersebut tidak baik di konsumsi dalam jumlah yang terlalu banyak.

3) Tempat penyajian mudah dibersihkan Wadah untuk makanan harus bersih tidak kotor, ke 3 pedagang di pasar Banjaran tidak terdapat tempat yang kotor, tempat keranjang atau wadah crystal living case dibersihkan setiap berjualan dan wadah crystal living case tersebut mudah di bersihkan, jika wadah untuk makanan sulit dibersihkan maka bakteri atau mikroba mudah timbulnya penyakit atau sarang penyakit, karena bakteri atau mikroba suka tempat-tempat yang kotor, selain itu jika tempat penyajian mudah dibersihkan maka kesehatan akan terjaga estetika penjamah makanan baik.

4) Penjual tidak terdapat luka (pada luka terbuka, bisul atau luka lainnya).

Jumlah 3 pedagang tidak terdapat luka, syarat makanan yang baik adalah makanan yang berkwalitas dan hygene makanan harus terjaga, agar makanan tersebut tidak mudah terkontaminasi oleh bakteri atau mikroba yang terdapat di penjamah makanan. Jika penjamah terdapat luka segeralah diobati dan luka tertutup, supaya bakteri tidak mudah terkontaminasi makanan.

5) Penjual tidak menggunakan alat bantu atau alat penjepit makanan

Jumlah 3 pedagang makanan jajanan tidak menggunakan alat penjepit makanan, alat tersebut adalah alat yang sangat penting untuk para pedagang, karena dapat mempengaruhi kualitas dan higyeni makanan yang disajikan. Penggunaan alat penjepit dapt mencegah terjadinya kontaminasi oleh bakteri maupun cemaran kimia lainnya, jika alat tersebut membersihkannya dengan bersih. Dengan demikian penjamah seharusnya menggunakan alat penjepit makanan agar upaya makanan tersebut tetap terjaga hygenenya.

6) Penjual memakai celemek pada saat berjualan

Jumlah 3 pedagang tidak memakai celemek, tetapi ke 3 pedagang hanya memakai pakaian biasa, Penggunaan celemek pada penjamah sangatlah penting karena dapat mempengaruhi kualitas makanan yang disajikan. 
Penggunaan celemek dapat mencegah terjadinya kontaminasi cemaran logam berat, cemaran mikotoksin, cemaran antipbiotik, cemaran sulfonamida atau cemaran kimia lainnya yang mungkin ada pada penjamah. Perilaku penjamah adalah salah satu pencegahan terjadinya kontaminasi pada makanan. Dengan demikian penjamah seharusnya lebih memperhatikan dan menyadari pentingnya penggunaan celemek dan tutup kepala agar makanan yang disajikan tidak terkontaminasi.

7) Penjual memakai tutup kepala pada saat berjualan.

Jumlah 3 pedagang makanan jajanan, penjamah yang tidak memakai tutup kepala ada 1 pedagang yaitu EK, penjamah seharusnya memakai penutup kepala, karena tutup kepala sangat penting untuk kwalitas dan hygene makanan, bertujuan untuk menghindari kontaminasi pada makanan jajanan yang dijual pedagang. Selain itu makanan yang disajikan terjaga hygenenya.

\section{SIMPULAN DAN SARAN}

\section{Simpulan}

Hasil pemeriksaan kadar $\mathrm{Pb}$ dari 24 sampel 3 pedagang makananjajanan, pengambilan 1 hari 2 kali yaitu pagi pukul 08.25 dan siang pukul 13.35, sampel tidak didapatkan kadar $\mathrm{Pb}$ bahwa sampel tersebut masih dibawah NAB BPOM RI No.HK.00.06.1.52.4011 tahun 2009 yaitu $\leq 0,25$ ppm. Kepadatan kendaraan ada 4 titik, pada titik 1 dikategorikan arus stabil untuk sepeda motor dan mobil dengan radius 30 meter yaitu $0,00 \mathrm{smp} / \mathrm{jam}$, pada titik 2 dikategorikan arus stabil untuk sepeda motor dan mobil dengan radius 35 meter yaitu 0,00 smp/jam, pada titik 3 dengan radius 30 meter dikategorikan arus stabil untuk sepeda motor yaitu 0,76 smp/jam dan mobil dikategorikan arus bebas yaitu 0,24 smp/jam, sedangkan pada titik 4 dengan radius 35 meter dikategorikan arus stabil untuk sepeda motor yaitu $0,71 \mathrm{smp} / \mathrm{jam}$ dan mobil dikategorikan arus bebas yaitu 0,17 smp/jam.

\section{Saran}

Saran bagi peneliti selanjutnya untuk pemeriksaan kadar $\mathrm{Pb}$ sebaiknya dalam mengukur kadar $\mathrm{Pb}$ menggunakan alat yang dapat mendeteksi Pd dalam kadar yang kecil, contohnya seperti metode AAS (atomic absorption spectrophotometry).

\section{DAFTAR PUSTAKA}

Annisa Filaeli,dkk,2012, Studi Kandungan Pb dalam gorengan yang dijual di pinggir jalan Tahun 2012, Universitas Negeri Yogyakarta:http://www.Scribd.com

BPOM RI No. HK.00.06.1.52.4011, Tentang NAB maksimal pada cemaran logam berat pada pangan.

Cahyadi, W. 2004. Upaya pencegahan pencemaran $\mathrm{Pb}$ pada makanan minuman.fakultas teknik Unpas Departemen farmasi pascasarjana ITB, http://www.pikiranrakyat.com/cetak/0804/1 9/cakrawala/utama1.html.19k

\section{Departemen Kesehatan RI,2001, Tentang makanan:http://Error! Hyperlink reference not valid.}

2002, Tentang mekanisme masuknya timbal dalam tubuh manusia:http://www.depkes.go.id/index.php ?act=regulation

Febriani B, Analisis kadar timbal pada jajanan gorengan dengan spektrofotometer serapan atom. STIKES Wira Medika Bali:http://www.Scribd.com

Habrianti, dkk. Konsentrasi Logam Berat Timbal (Pb) Dalam Makanan Jajanan, Kerang Andara sp. Dan Urine Siswa SD Negeri Tallo Tua $69 \quad$ Makassar [Skripsi].Makassar:Universitas Hasanuddin; 2013, http://repository.unhas.ac.id/handle/123456 $789 / 5527$

Heryando P,1994, Pencemaran dan Toksikologi Logam Berat,Jakarta:PT Rineka Cipta.

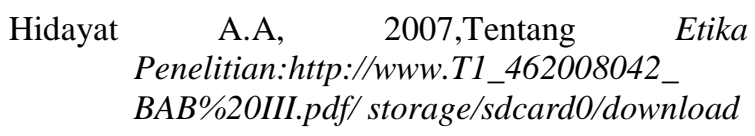

$$
\begin{array}{ccr}
\text { http://www.arus } \quad \text { stabil dalam } & \text { kepadatan } \\
\text { kendaran.co.id/download.PDF } & \text { diakses } \\
\text { tanggal 12 juli 2016; 13.44 WIB. } &
\end{array}
$$

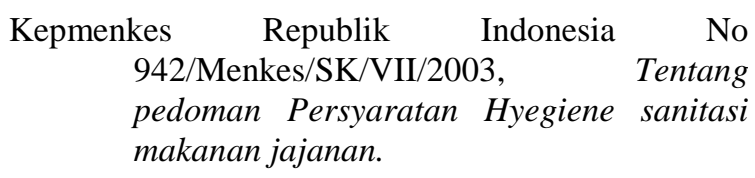

K.irianto.2007.tentang makanan jajanan. http://www.landasanteori.com/2015/08/ pengertian-makanan-jajanan-jenisciri.html?m=1 
Marwanti, dkk, 2004, Tingkat pencemaran Timbal (Pb) pada makanan jajanan di pasar Berngharjo Tahun 2004, Universitas Negeri Yogyakarta.

Marbun MB, 2010, Tentang faktor hubungan $\mathrm{Pb}$ pada makanan jajanan,

http://www. JURNAL.pdf/storage/sdcard0/PDF

Peraturan UU RI No 36 Tahun 2009 tentang kesehatan. http:/www.slideshare.net/ mobile/ichsansudjarno/uu-kesehatan-n0-36thn-2009

, No.23 Tahun 1997, Tentang Pencemaran udara.http://www.hukum.unsrat.ac.id/uu/uu _23_97.htm

PT. Tranadi Tatautami, 2012, tentang tingkat pelayanan jalan.

Putraprabu,2008,Tentang makanan menurut WoldHealt Organization:http://www. chapter\%20ii-

1.pdf/strone/sdcard0/download

Sastrawijaya T. pencemaran Udara. Jakarta: Rieneka Cipta;2000

Soedomo M, 2001, Pencemaran udara. Bandung: ITB; 2001

Suharsimi Arikunto, 2006, Prosedur Penelitian, Jakarta : PT. Rineka Cipta.

Tri Cahyono, 2014, pedoman penulisan proposal penelitian dan karya tulis ilmiah/skripsi

Triyani N, 2013, Analisis kandungan Timbal (Pb) pada makanan yang dijual pedagang kaki lima disepanjang jalan dr.soeparno dan jalan kampus tahun 2013, Universitas Jenderal Soedirman Purwokerto:http://www.Scrib. 